\title{
Spot-on Emulsion Dosage Form
}

National Cancer Institute

\section{Source}

National Cancer Institute. Spot-on Emulsion Dosage Form. NCI Thesaurus. Code C149944.

Liquid preparation consisting of an emulsion intended for spot-on use for the prevention and treatment of ectoparasitic and/or endoparasitic infestations of animals. Spot-onemulsions are applied in volumes that are usually less than $10 \mathrm{~mL}$. 